\title{
Özdüzenleyici Haritalar Yardımıyla Piyasa Bölümlendirmesi: Türkiye İkinci El Otomobil Piyasası Örneği
}

Özdüzenleyici Haritalar Yardımıyla Piyasa Bölümlendirmesi: Türkiye İkinci El Otomobil Piyasası Örneği

Öz

İkinci el araç alım satımı ile ilgilenen kişi ve kurumlar, gerçekleştirdikleri işlemlerde başarılı olabilmek için, piyasanın yapısını iyi anlamak durumundadırlar. Literatürde ikinci el otomobillerin satış fiyatını tahmin eden çalışmalar olmasına rağmen, ikinci el piyasada satışa sunulan otomobillerin kümelendirilmesine ilişkin bir çalışmaya rastlanmamıştır. Bu nedenle bu çalışmada, Temmuz 2016 tarihinde ilana çıkan 65931 adet ikinci el veya sıfır otomobile ilişkin altı adet değişkenden oluşan veri seti bir araya getirilmiş ve araçlar yapay sinir ağları tabanlı özdüzenleyici haritalar yöntemi ile kümelere ayrılmıştır. Çalışma sonucunda ortaya çıkan kümeler istatistiksel açıdan da incelenmiş ve kümelerin birbirlerinden farklı olduğu sonucu ortaya çıkmıştır. Çalışmada elde edilen sonuçlar kaynaklarını etkin bir şekilde kullanmak durumunda olan ikinci el otomobil alım satımı ile uğraşan kişi ve kurumlara, kaynaklarını etkin yönetebilmelerini sağlayacak bilgiler sunmaktadır.

Anahtar Kelimeler: Yapay Sinir Ağları, Özdüzenleyici Haritalar, Piyasa Bölümlendirilmesi, İkinci El Otomobil
Market Segmentation with Self-Organizing Maps: Sample of Turkey's Used Car Market

Abstract

Individuals and institutions that are interested with trading used cars must understand the structure of the market to become successful at their transactions. Although there are various studies that aim to predict the sales price of used cars, there is no available study regarding the segmentation of used car market. Six variables belong to 65931 used cars are collected from one of the major e-commerce website in Turkey on July 2016. Used car market segmented using self-organizing maps technique which is a special kind of artificial neural networks. The clustering results are also investigated with statistical techniques and it is concluded that clusters are statistically different from each other. The results obtained in the research presents useful knowledge to the individuals and institutions operating in used car market to manage their resources effectively.

Keywords: Artificial Neural Networks, Self-organizing Maps, Market Segmentation, Used Car

\section{Giriş}

İkinci el araç alım satımı ile ilgilenen kişi ve kurumlar, işlemlerinde başarılı olabilmek için ikinci el otomobil piyasasının yapısını iyi bilmek zorundadırlar. İkinci el otomobil piyasasını iyi tanımak, söz konusu piyasada işlem yapan alıcı ve satıcılara yol gösterecektir. Üstelik bazı durumlarda, aracın ikinci el piyasasındaki durumu, birinci el araç satışını bile etkileyebilmektedir. Bu nedenle ikinci el araç piyasasının modellenmesi, araçlarını satmayı düşünenler ve alım satımla ilgilenen kurumlar açısından oldukça önemlidir. Literatürde ikinci araçların ikinci el satış fiyatını tahmin etmeye yönelik çalışmalar mevcuttur (Asilkan ve Irmak, 2009; Daştan, 2016; Ecer, 2013; Erdem ve Şentürk, 2009). Buna rağmen ikinci el araç piyasasında satışa sunulan araçları kümelemeye yönelik bir çalışmaya rastlanmamıştır. Literatürde var olan bu açığı kapatmak adına, bu çalışmada Türkiye'deki ikinci el oto piyasasında yer alan araçlar, yapay sinir ağlarının özel bir çeşidi olan özdüzenleyici haritalar tekniği yardımıyla kümelendirilmiştir. Bu şekilde piyasa bölümlendirmesi gerçekleştirmek, alım satımla ilgilenen kurumlar için pazarlama stratejilerine şekil verecekken, araçlarını satmayı düşünen bireylerin de piyasanın genel durumu hakkında bilgi sahibi olmalarını sağlayacaktır.

\footnotetext{
${ }^{1}$ Yrd. Doç. Dr., Kilis 7 Aralık Üniversitesi iiBF, Uluslararası Ticaret ve Lojistik Bölümü, mozcalici@kilis.edu.tr
} 
Pazarlamanın temel stratejilerinden bir tanesi müşterileri homojen gruplara ayırmaktır (Everitt vd., 2011:9). Bölümlendirme ile pazarlama araştırmacısı bütün piyasayı tek tek incelemek yerine kümelerden seçilen kişilerle iletişime geçebilir ve piyasa hakkında bilgi sahibi olabilir. Aynı şekilde, hisse senetleri finansal karakterlerine göre kümelendirildiğinde, portföy yöneticilerinin işlemlerini gerçekleştirirken yol gösterici bir rol oynayabilir. Pazar analizi ile birlikte kısıtlı olan kaynaklar etkin bir şekilde kullanılmaktadır ve piyasa bölümlendirme işlemi ise pazar analizinin bir alt başlığı olarak karşımıza çıkmaktadır (Fill, 2009: 291).

Pazar bölümlendirme için kümeleme analizinden faydalanılmaktadır. Kümeleme literatürde; kümeleme analizi, bölümlendirme analizi, sınıflandırma (taxonomy) veya gözetmensiz sınıflandırma (unsupervised classification) gibi isimlerle adlandırılmaktadır ve nesneleri kümelere ayırmakta kullanılan bir yöntemdir. Bu kümeleme işlemi sonunda aynı kümede yer alan nesnelerin birbirleriyle benzer özellikler taşıması ve farklı kümelerdeki nesnelerin ise birbirlerinden farklı olması beklenmektedir (Gan vd., 2007: 3).

K-ortalamalar yöntemi kümeleme analizinde sıklıkla kullanılan ve temel nitelikte bir analizdir (Yeh vd., 2016). K-ortalamalar yönteminde kümeleme analizine konu olan nesneler arasındaki uzaklık ve küme merkezleri arasındaki uzaklıklar dikkate alınmakta ve veri seti $k$ adet kümeye ayrılmaktadır. Her ne kadar k-ortalamalar yönteminin uygulaması basit olsa ve yaygın bir şekilde kullanılsa da bazı dezavantajları mevcuttur. Örneğin, analizin uygulayıcısı k küme sayısını belirlemek durumundadır. Bu durum, kullanıcının veri seti hakkında önceden bilgiye sahip olmasını gerektirmektedir. Bununla birlikte, başlangıç aşamasında seçilen örnekler yöntemin performansı üzerinde etkilidir (Everitt vd, 2011: 125). Başka bir ifade ile farklı başlangıç durumlarında model farklı sonuçlar üretebilmektedir. K-ortalamalar yönteminin sahip olduğu bu dezavantajlardan dolayı kümeleme analizinde özdüzenleyici haritalar gibi yapay zekâ tekniklerinin kullanılması gerekmektedir (Ince vd., 2013).

Özdüzenleyici haritalar yöntemi kümeleme alanında kullanılan yapay sinir ağları temelli bir yöntemidir. Özdüzenleyici haritalar (Self-Organizing Maps (SOM)), mikrofinans kurumlarının sosyal etkisi ve finansal etkinliğinin ölçülmesi (Louis vd., 2013), yatırım fonları piyasasının modellenmesi ve simulasyonu (Chen vd., 2013), müşteri hizmetleri çağrı merkezi piyasasının bölümlendirilmesi (Xia vd., 2015), ADSL pazarının bölümlendirilmesi (Hanafizadeh ve Mirzazadeh, 2011), dünya şehirlerinin kıyaslanması (Arribas-Bel vd., 2013), elektrik yükünün sınıflandırılması (Dragomir vd., 2014) ve benzeri birçok alanda başarı ile kullanılmaktadır. Üstelik tüketici profilleme örneğinde özdüzenleyici haritalar yönteminin, k-ortalamalar yöntemine göre daha iyi performans sergilediği kanıtlanmıştır (İnce vd., 2013). Bu nedenle bu çalışmada kümeleme analizini gerçekleştirmek için özdüzenleyici haritalar yöntemi seçilmiştir. Özdüzenleyici haritalar yönteminin piyasa bölümlendirilmesinde kullanılmasının bazı faydaları mevcuttur. Örneğin kullanıcı, analizi kullanırken, pazarın kaç adet kümeye ayrılacağını analize başlamadan önce belirlemek durumunda kalmayacaktır. Bununla birlikte ortaya çıkan haritalar çok boyutlu veri setini iki boyuta indirgemektedir ve bu durum da ikinci el otomobil piyasasının görsel bir şekilde değerlendirilmesine olanak sağlamaktadır.

Çalışma dört bölümden oluşmaktadır. Bu giriş bölümünden sonra ikinci bölümde literatürde yapılan çalışmalar incelenmektedir. Üçüncü bölümde analiz yöntemi veri seti ve analiz sonuçlarına yer verilecektir. Sonuç bölümünde ise çalışmada ortaya çıkan sonuç, çalışmanın kısıtları ve sonraki çalışmalar için öneriler yer almaktadır. 


\section{Literatür İncelemesi}

Özdüzenleyici haritalar (self-organizing maps - SOM) isminin Türkçe literatürde birden fazla karşılığı bulunmaktadır. Başka bir ifade ile kavramın Türkçe ismi konusunda bir birliktelik söz konusu değildir. Türkçe literatür incelendiğinde, self-organizing maps ifadesinin, kendinden düzenlenen haritalar (Alpdoğan ve Bilge, 2009), özörgütlemeli harita ağları (self-organizing feature maps) (Demirhan ve Güler, 2010), özörgütlenmeli haritalar (Canbaz ve Çevik, 2011), öz-düzenlemeli harita ağları (İnce vd., 2013), kendini düzenleyen haritalar (Kohonen Ağları) (Oğuzlar, 2009; Taşkın ve Emel, 2010), kendini örgütleyen haritalar (Özşahin ve Yüreğir, 2012), SOM tipinde yapay sinir ağları (Bircan vd, 2006) ve özdüzenleyici haritalar (Özçalıcı, 2011; Özçalıcı, 2016; Kutlu vd., 2008; Kutlu vd., 2009) gibi isimlerle adlandırıldığı görülmektedir.

Kümeleme algoritmaları yardımıyla piyasa bölümlendirme hakkında birçok çalışma gerçekleştirilmiştir. Bu çalışmalardan bazılarını şu şekilde özetlemek mümkündür. Ünal ve Erciş (2004) çalışmalarında banka müşterilerini bölümlendirmişlerdir. Çalışmalarının ana kütlesi bankacılık hizmetlerinden faydalanan müşterilerden oluşmaktadır. 604 adet kişiyle anket çalışması gerçekleştirmişlerdir. Kümeleme analizi olarak k-ortalamalar yöntemini kullanmışlardır. Çalışmalarının sonunda banka müşterilerinin farklı özellikler sergiledikleri ve banka yöneticilerinin de bu durumu dikkate almak suretiyle uygun stratejiler belirlemeleri gerektiği sonucuna ulaşmışlardır.

Öz ve arkadaşları (2008) çalışmalarında Türkiye ve AB ülkelerinin karşılaştırılmasında kümeleme analizini kullanmışlardır. Eğitim, sağlık ve işgücü piyasalarına ilişkin göstergeleri kullanmak suretiyle Türkiye ve $A B$ üyelerinin bir karşılaştırılmasını yapmışlardır. Hiyerarşik kümeleme analizini kullanmışlardır. Beşerî sermaye açısından, Türkiye’nin diğer AB üyesi ülkelerden ayrı bir yerde durduğu sonucuna ulaşmışlardır.

Taşkın ve Emel (2010) çalışmalarında Kohonen ağları ile parakendecilik sektöründe bir kümeleme uygulaması gerçekleştirmişlerdir. Bir işletmenin 10000 adet müşterisine ait veri tabanı kullanılmış ve Kohonen tekniği ile kümeleme gerçekleştirilmiştir. Şekerkaya ve Cengiz (2010) ise çalışmalarında kadın tüketicilerin alışveriş merkezi tercihlerine göre kümenmesi problemi üzerinde durmaktadırlar. 304 adet AVM müşterisine anket uygulamışlardır ve kümeleme aracı olarak k-ortalamalar yöntemini kullanmışlardır.

Eklund ve arkadaşları (2011) Avrupa'daki kâğıt endüstrisinde faaliyet gösteren şirketleri özdüzenleyici haritalar yöntemi ile kümelere ayırmışlardır. 196 adet şirkete ilişkin finansal oranları kullanmışlardır.

Özşahin ve Yüreğir (2012) Türkiye'de otomotiv sektöründe faaliyet gösteren firmaları, bilanço ve gelir tablolarından elde edilen finansal oranları kullanmak suretiyle özdüzenleyici haritalar yöntemi ile kümelere ayırmıştır.

İnce ve arkadaşları (2013) çalışmalarında tüketici profilleme çalışması gerçekleştirmişlerdir. Çalışmalarında öz-düzenlemeli harita ağları ve k-ortalama yöntemlerini kullanmak suretiyle, tüketicilerin alışveriş motivasyonu ile birlikte karar verme stillerine dayalı tüketici profili çıkarılmıştır. Toplamda 1459 adet müşteriyle anket gerçekleştirilmiş ve tüketici profilleri oluşturulmuştur. Sonuçta öz-düzenlemeli haritalar yönteminin, k-ortalamalar yöntemine göre daha üstün sonuçlar ortaya çıkardığı raporlanmaktadır.

Arı ve arkadaşlarının çalışmasında (2016), Borsa İstanbul'da faaliyet gösteren 90 adet firma, finansal tablolarından elde edilen bilgileri kullanmak suretiyle kümelere ayrılmıştır. Çalışmalarında iki aşamalı kümeleme yöntemini kullanmışlardır. Özçalıcı (2016) yaptığı çalışmada 
BIST 50 Endeksinde listelenen hisse senetlerini kümelere ayırmak amacıyla özdüzenleyici haritalar yöntemini kullanmıştır. Çalışmada etkin portföy oluşturma problemi üzerinde durulmuş ve özdüzenleyici haritalar yönteminin birbirlerine benzeyen hisse senetlerinin aynı kümede, birbirlerine benzemeyen senetlerin de farklı kümelerde toplayabildiği ifade edilmektedir. Çalışmada ayrıca diğer görsel ve istatistiksel yöntemler kullanmak suretiyle özdüzenleyici haritalar yönteminin başarılı bir kümeleme gerçekleştirildiği raporlanmaktadır.

Literatürdeki bu çalışmalar göz önünde bulundurulduğunda, ikinci el oto piyasasında satışa sunulan araçlara ilişkin bir veri seti kullanmak suretiyle kümeleme analizinin gerçekleştirilmediği anlaşılmaktadır.

\section{Araştırmanın Yöntemi}

\subsection{Prosedür}

Özdüzenleyici haritalar, veri setindeki doğrusal olmayan ilişkileri düşük boyutlara indirgeyen bir bilgi işlemsel veri analiz (computational data analysis) yöntemidir (Kaski, 2011:886). Basitçe ifade etmek gerekirse girdi setinin benzerlik grafiğini oluşturmaktadır (Kohonen, 2001: 106).

Özdüzenleyici haritalarda, bitişik nöronların benzer ağırlık vektörüne sahip olacağı bir rekabetçi öğrenme (competitive learning) prensibini uygulanmaktadır. Öğrenme sürecinde en yüksek düzeyde aktive edilen nöron (rekabeti kazanan nöron) ve bu nörona komşu olan nöronlar, ağa sunulan örneğe doğru hareket etmektedir. (Mehrotra vd., 1996: 188). SOM eğitim algoritması, ağa yeni bir örnek sunulduğunda kazanan nöronu ve komşularını güncellemektedir (Mehrotra vd., 1996: 188).

Özdüzenleyici haritalar, girdi katmanı ve Kohonen katmanı (çıktı katmanı) olmak üzere iki katmandan oluşmaktadır. Girdi katmanındaki her bir nöronun çıktı katmanındaki nöronlarla bağlantısı vardır. Kohonen katmanının girdisi şu şekilde hesaplanabilir:

$$
y_{i}=\sum_{i=1}^{d} w_{j i} z_{i}
$$

formülde, $w_{j i}$ ifadesi, girdi nöronu $i$ den, çıktı nöronu $j$ ye olan ağırlığı ve $z_{i}$ normalleştirilmiş girdi değerini ifade etmektedir. Rekabetçi öğrenme sürecinde ise en yüksek $y_{i}$ değerine sahip nöron kazanan nöron olarak adlandırımaktadır (Gan vd., 2007: 56).

Şekil 1'de özdüzenleyici haritaların temel yapısı görselleştirilmeye çalışılmıştır. Şekilde 9x7 nörondan oluşan çıktı (Kohonen) katmanı görülmektedir. Normalleştirilmiş girdi vektörü $z$ ile temsil edilmektedir. Ağırlık vektörü $w$ ile temsil edilmektedir ve girdi katmanındaki her bir nörondan çıktı katmanındaki her bir nörona giden ağırlıkları barındırmaktadır. $c$ kazanan nöronu temsil etmektedir ve çevresindeki nöronlar ise $c^{\prime}$ nin komşularıdır. 
Şekil 1. Özdüzenleyici haritalar temel yapısı (Badran vd., 2005:407).

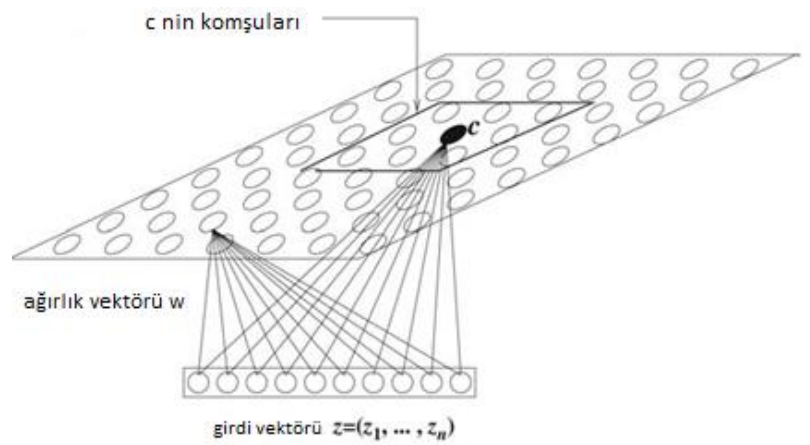

Özdüzenleyici haritalar kolay anlaşılabilir bir yapıya sahip grafikler ortaya çıkarmaktadır ancak detaylı analizleri oldukça zordur. Geleneksel birçok analizle bağlantı kurmak mümkündür ve pratikte de iyi bir şekilde uygulanabilmektedir ve birçok farklı türleri ortaya çıkmıştır (Kaski, 2011: 886).

\subsection{Veri Seti}

Çalışmanın amacı, Türkiye'de yer alan ikinci el otomobil piyasasını özdüzenleyici haritalar yardımıyla modellemektir. Bu amacı gerçekleştirmek için hazır bir veri seti bulunmamaktadır. Bu nedenle veri seti, Türkiye'de faaliyet gösteren e-ticaret sitelerinden olan sahibinden.com sitesinde yayınlanan ilanlardan derlenmiştir. Sitede 2016 Temmuz ayında 105000 adetten daha fazla ikinci el veya sıfır oto satış ilanı mevcut bulunmaktadır. Bazı ilanlarda tam bilgi yer alırken, bazı ilanlarda eksik bilgiler yer almaktadır. Başka bir ifade ile eksik bilgi söz konusudur. Analiz gerçekleştirilmeden önce bu ilanların veri setinden çıkarılması gerekmektedir. Temizleme işleminden sonra veri setinde, 65931 adet araca ilişkin ilan yer almıştır. Araçların markalarına ilişkin tanımlayıcı bilgiler Tablo 1'de yer almaktadır.

Tablo 1. Çalışmada yer alan ilanların markalara göre dağılımı

\begin{tabular}{|c|c|c|c|c|c|}
\hline Model & Frekans & Yüzde (\%) & Model & Frekans & Yüzde (\%) \\
\hline Alfa Romeo & 285 & 0,4323 & Mercedes-Benz & 120 & 0,1820 \\
\hline Audi & 570 & 0,8645 & Nissan & 699 & 1,0602 \\
\hline Chevrolet & 2022 & 3,0668 & Opel & 6337 & 9,6116 \\
\hline Citroën & 2080 & 3,1548 & Peugeot & 3375 & 5,1190 \\
\hline Dacia & 1106 & 1,6775 & Renault & 11592 & 17,5820 \\
\hline Fiat & 6732 & 10,2107 & Toyota & 3958 & 6,0030 \\
\hline Ford & 8334 & 12,6409 & Volkswagen & 8214 & 12,4585 \\
\hline Honda & 1532 & 2,3236 & Volvo & 206 & 0,3124 \\
\hline Hyundai & 5465 & 8,2890 & Skoda & 772 & 1,1709 \\
\hline Kia & 926 & 1,4045 & Seat & 1353 & 2,0521 \\
\hline Mazda & 253 & 0,3837 & Toplam & 65931 & 100 \\
\hline
\end{tabular}

Çalışmada kullanılacak araçlar belirlendikten sonra hangi değişkenlere göre kümelemenin gerçekleştirilmesi gerektiği problemi ortaya çıkmaktadır. Değişkenleri belirlemek için uzman görüşünden faydalanılmıştır. İkinci el araç alım satımı ile ilgilenen iki adet uzmanla birebir görüşülmüş ve çalışmanın içeriği anlatılmıştır. Uzmanlar farklı firmalarda çalışmaktadırlar ve 
her birisinin on yıldan fazla satış tecrübesi bulunmaktadır. İki tur şeklinde yapılan tartışmalar sonucunda bu çalışma için 6 adet değişkenin kullanılması gerektiği sonucuna varılmıştır. Bu değişkenlerden sayısal olanlara ilişkin tanımlayıcı istatistikler Tablo 2'de yer almaktadır. Sayısal değişkenler için aracın satış fiyatı, aracın yaşı ve motor hacmi seçilmiştir. Kategorik değişkenlerden ise aracın ABS, ESP ve Yokuş Kalkış desteği sistemlerine sahip olup olmadıkları uzmanlar tarafından uygun görülmüştür. Kategorik (ikili) değişkenlere ilişkin tanımlayıcı istatistikler ise Tablo 3'de yer almaktadır.

Tablo 2. Çalışmada kullanılan sayısal değişkenlere ilişkin tanımlayıcı istatistikler

\begin{tabular}{lrrrr}
\hline & Minimum & Maximum & Ortalama & Standart Sapma \\
\hline \hline Fiyat & 1560 & 70000 & 42987,0 & 12135,00 \\
YIl & 2000 & 2016 & 2011,2 & 2,97 \\
Motor Hacmi & 1086 & 2000 & 1452,1 & 144,54 \\
\hline
\end{tabular}

Tablo 3. Çalışmada kullanılan ikili değişkenlere ilişkin tanımlayıcı istatistikler

\begin{tabular}{lcrr}
\hline Değişken & & Frekans & Yüzde \\
\hline \hline ABS (Antilock Braking System) & Var & 61277 & 92,94 \\
& Yok & 4654 & 7,06 \\
EPS (Electronic Stability Program) & Var & 32085 & 48,66 \\
& Yok & 33846 & 51,34 \\
Yokuş Kalkış Desteği & Var & 20519 & 31,12 \\
& Yok & 45412 & 68,88 \\
\hline
\end{tabular}

Çalışmada kullanılan bütün değişkenlerin ölçekleri birbirlerinden farklıdır. Veri seti, analizde kullanılmadan önce aşağıdaki formül yardımıyla [0,1] aralığında normalleştirilmiş ve ölçeklerden arındırılmıştır (Gan vd 2007: 46).

$$
X_{y e n i}=\frac{X_{e s k i}-X_{\min }}{X_{\max }-x_{\min }}
$$

\subsection{Veri Analizi}

Özdüzenleyici haritalarda kaç adet nöronun kullanılması gerektiğine ilişkin bir formül mevcut değildir. Bu nedenle Hanafizadeh ve Mirzazadeh (2011) çalışmasında kullanıldığı gibi bu çalışmada da deneme yanılma yolu tercih edilmiştir. Çalışmada bazı denemeler yapılmış ve veri setinin kümelere en belirgin şekilde ayrıldığı nöron bileşenin 20x10 adet olduğuna karar verilmiştir.

Çalışmada analizi gerçekleştirmek için MATLAB yazılımından faydalanılmıştır. Özdüzenleyici Haritalar, MATLAB yazılımında yerleşik bulunan Neural Networks Araç Kutusu (Toolbox) ile oluşturulmuştur. Eğitim algoritması olarak Batch Weight/Bias Rules eğitim algoritması kullanılmıştır. Performans fonksiyonu olarak Ortalama Karesel Hata (Mean Squared Error) performans göstergesi kullanılmıştır. En yüksek epoch sayısı 200 olarak kabul edilmiştir.

\subsection{Araştırmanın Bulguları ve Sonuçları}

Şekil 2'de SOM Neighbor Weight Distances (SOM Komşuluk Ağırlık Uzaklıkları) (U Matris Kohonen Katmanı) ve Hit Rate (Her bir nöronda hangi otomobilin olduğunu gösteren grafik) yer almaktadır. Komşuluk ağılık uzaklıkları haritası adı üzerinden de anlaşılabileceği gibi her bir nöronun (ve dolayısıyla nöronların içerdiği gözlemlerin) birbirlerine ne kadar uzak olduğunu 
göstermektedir. Bu harita aynı zamanda çıktı katmanı olarak adlandırılmaktadır. Bu haritadaki ağılık değerin sıfır olması komşuların birbirleri ile uzak olduğunu (hiç yakın olmadığını) ifade etmektedir. Bu nedenle bu şekildeki siyah veya koyu renkler kümelerin sınırlarını belirtmektedir. Aynı şekilde açık renkli bağlantılar nöronların içerdiği gözlemlerin birbirleri ile yakın olduğunu göstermektedir. Başka bir ifade ile açık renkli alanlar kümeleri içermektedir. Hit rate şeklinde ise hangi nöronda hangi gözlemin yer aldığını ifade etmektedir.

Şekil 3'de ise girdi panelleri yer almaktadır. Bu panellerde de girdilere göre nöronlardaki gözlemlerin değerlerinin dağılımları görselleştirilmektedir. Açık renkli değerler o nöronlarda yer alan nesnelerin yüksek değerlere sahip olduğunu, koyu renkler ise o nöronlarda yer alan nesnelerin düşük değere sahip olduğunu göstermektedir.

Şekil 2. SOM Komşuluk Ağırlıkları ve Hit Çizelgesi
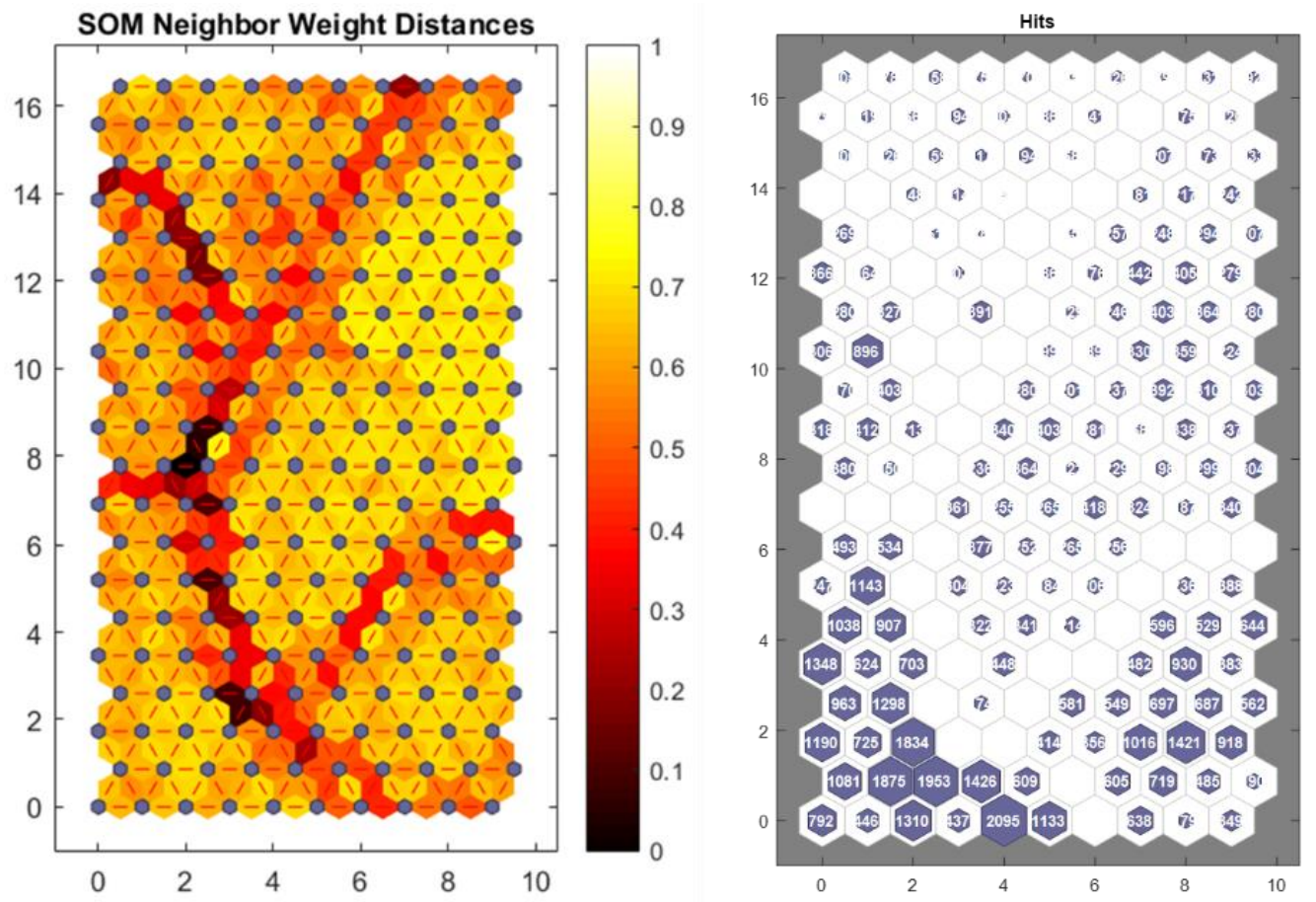
Şekil 3. SOM Girdi Panelleri
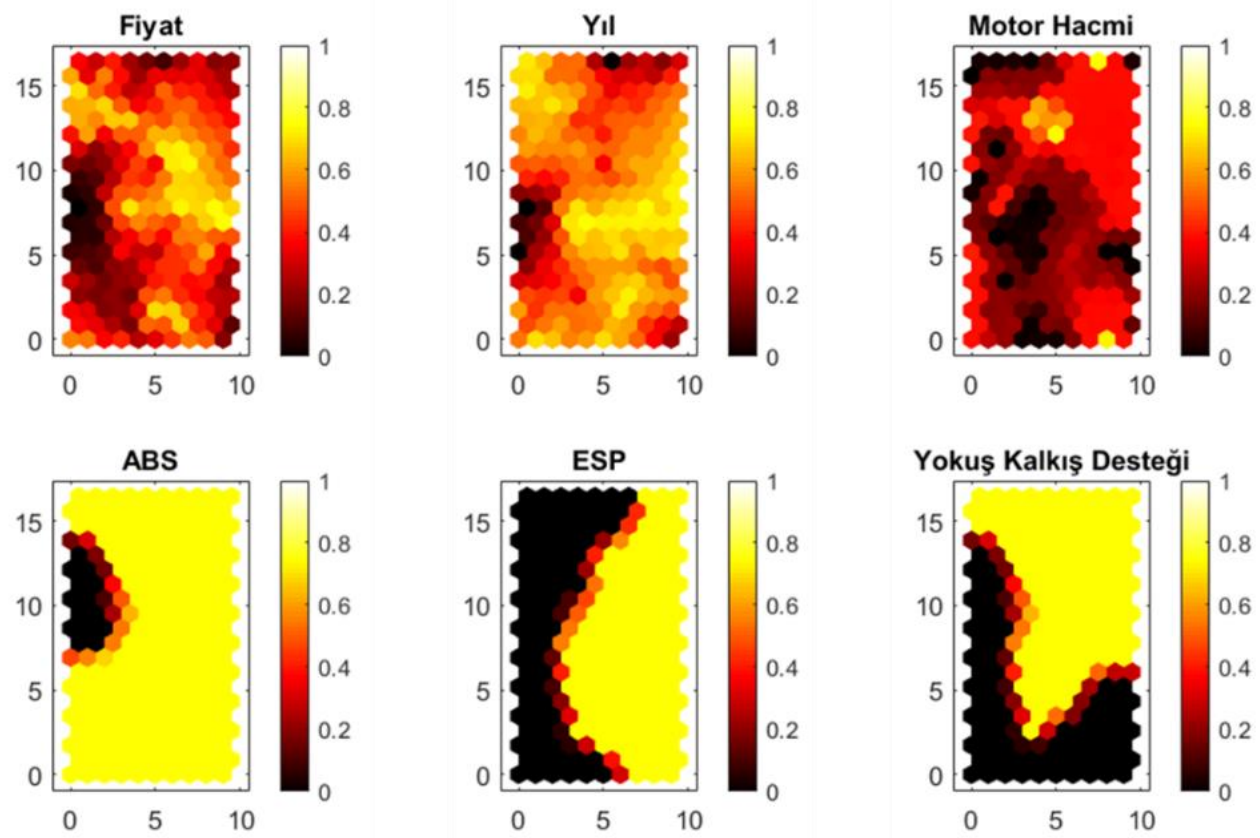

\subsection{Kümelerin Belirlenmesi ve Özellikleri}

Analiz sonucundaki görseller bu şekilde sunulduktan sonra sıra kümelerin yerlerinin belirlenmesine gelmektedir. Analiz sonucunda ortaya çıkan $U$ matris ve hit rate görselleri kümelerin yerlerinin belirlenmesinde kullanılmaktadır. U matristeki koyu renkli nöronları ve hit rate görselindeki boş nöronları bir arada düşündüğümüzde küme sınırları Şekil 4'deki gibi ortaya çıkmaktadır.

Küme yerleri belirlendikten sonra sıra, kümelere ilişkin tanımlayıcı istatistiklerin incelenmesine gelmektedir. Bu aşamada her kümede yer alan otomobillerin genel durumu incelenmektedir. Ayrıca her küme sahip olduğu belirgin özellikler göz önünde bulundurulmak suretiyle isimlendirilecektir. Tablo 4'de kümelerde yer alan araçlara ilişkin özellikler özet olarak sunulmuştur. 
Şekil 4. Küme yerlerinin belirlenmesi
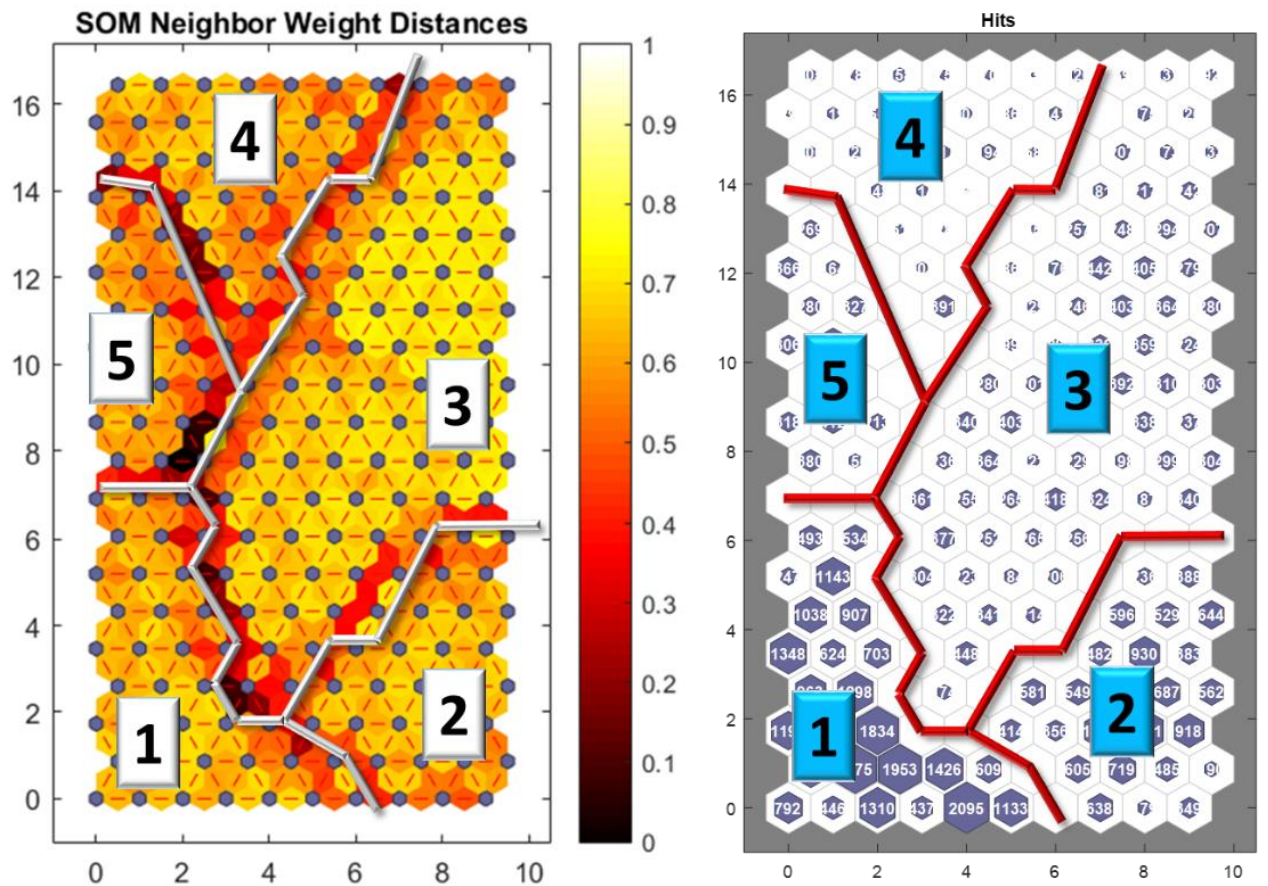

Tablo 4. Kümeler ve Özellikleri

\begin{tabular}{|c|c|c|c|c|c|c|}
\hline & & Küme1 & Küme 2 & Küme 3 & Küme 4 & Küme 5 \\
\hline & Araç Sayısı & 26204 & 14554 & 17531 & 2988 & 4654 \\
\hline & Küme Yüzdesi & 39,74 & 22,07 & 26,59 & 4,53 & 7,06 \\
\hline \multirow{4}{*}{ Fiyat } & Min & 1560 & 11750 & 2100 & 17950 & 2500 \\
\hline & Max & 70000 & 70000 & 70000 & 70000 & 70000 \\
\hline & Ortalama & 36289,81 & 46108,27 & 52905,28 & 45563,73 & 31917,77 \\
\hline & Std Sapma & 8685,68 & 9569,93 & 10165,96 & 9686,75 & 12047,37 \\
\hline \multirow{4}{*}{ Yıl } & Min & 2000 & 2000 & 2000 & 2000 & 2000 \\
\hline & Max & 2016 & 2016 & 2016 & 2016 & 2016 \\
\hline & Ortalama & 2010,27 & 2011,72 & 2012,75 & 2011,52 & 2008,85 \\
\hline & Std Sapma & 3,07 & 2,2 & 2,06 & 2,83 & 3,91 \\
\hline \multirow{4}{*}{ Motor Hacmi } & Min & 1086 & 1086 & 1086 & 1086 & 1086 \\
\hline & Max & 2000 & 2000 & 2000 & 2000 & 2000 \\
\hline & Ortalama & 1412,68 & 1501,87 & 1473,63 & 1471,86 & 1425,2 \\
\hline & Std Sapma & 139,91 & 132,45 & 145,22 & 141,5 & 139,26 \\
\hline \multirow{2}{*}{$A B S$} & Var & 26204 & 14554 & 17531 & 2988 & 0 \\
\hline & Yüzde (\%) & 42,76 & 23,75 & 28,61 & 4,88 & 0 \\
\hline \multirow{2}{*}{ ESP } & Var & 0 & 14554 & 17531 & 0 & 0 \\
\hline & Yüzde (\%) & 0 & 45,36 & 54,64 & 0 & 0 \\
\hline \multirow{2}{*}{ Yok. K. Dest. } & Var & 0 & 0 & 17531 & 2988 & 0 \\
\hline & Yüzde (\%) & 0 & 0 & 85,44 & 14,56 & 0 \\
\hline
\end{tabular}

Kümelerin özellikleri ve isimlendirmesini şu şekilde gerçekleştirmek mümkündür. 
Küme 1 (Yaygın Araçlar): En fazla aracın yer aldığı küme bu kümedir. Ortalama olarak 2010 model araçların yer aldığı bu kümede fiyat ortalamasının da 36000 TL civarında olduğu görülmektedir. Bu kümede yer alan araçların motor hacmi ortalama $1412 \mathrm{~cm}^{3}$ tür. Bu gruptaki her araçta ABS sistemi olmasına rağmen, hiçbir araçta ESP ve kokuş kalkış desteği bulunmamaktadir.

Küme 2 (Güçlü Motor): İncelenen araçların \%22,07 sinin yer aldığı kümedir. Bu kümedeki araçların ortalama fiyatı 46000 TL civarındadır ve motor hacimleri ortalama $1501 \mathrm{~cm} 3$ tür. Ortalama model yılı 2011'dir. Her araçta ABS ve ESP sistemi varken, hiçbir araçta yokuş kalkış desteği yoktur. Bu özellikler göz önünde bulundurulduğunda küme 1'den daha üst modeldeki araçların yer aldığını söylemek mümkündür.

Küme 3 (Modern Araçlar): İncelenen araçların \%26,59 u bu kümede yer almaktadır. Dolayısıyla en geniş hacme sahip ikinci kümedir. Araçların ortalama fiyatı 52000 TL civarındadır. Model yıllarının ortalamasının 2012 olduğu görülmektedir. İstisnasız her araçta ABS, EPS ve yokuş kalkış desteği bulunmaktadır. En pahalı ve en yeni araçlar bu kümede yer almaktadır. Bu kümede yer alan araçların ortalama motor hacimlerinin $1473 \mathrm{~cm} 3$ olduğu görülmektedir.

Küme 4 (Yarı-Modern): Bu kümede 2988 adet araç bulunmaktadır ve az aracın yer aldığı küme bu kümedir. Ortalama $45000 \mathrm{TL}$ civarındaki araçların motor hacimlerinin ortalamasının $1471 \mathrm{~cm} 3$ olduğu ve araçların model yıllarının ortalama 2011 olduğu anlaşılmaktadır. Araçlarda ABS ve yokuş kalkış desteği bulunmaktadır, ESP ise bulunmamaktadır.

Küme 5 (Eski Araçlar): İkinci en düşük hacme sahip küme bu kümedir. Incelenen araçların $\% 7,06$ sı bu kümede yer almaktadır. Ortalama fiyatlarının 31000 TL civarında olduğu görülmektedir. Araçların model yılları ortalama 2008 olarak hesaplanmıştır. Motor hacimleri ise $1425 \mathrm{~cm}^{3}$ tür. Hiçbir araçta ABS, ESP ve yokuş kalkış desteği bulunmamaktadır.

Kümelerde yer alan sayısal değişkenlerin birbirlerinden farklı olup olmadığını ölçmek için ANOVA analizi gerçekleştirilmiştir. Sürekli değişkenlere ilişkin ANOVA testi sonuçları Tablo 5 'deki gibidir. Tablodaki sonuçlara göre fiyat $(F=9849,91, p<0,01)$, araçların model yılları $(F=3197,22, p<0,01)$ ve motor hacimleri $(F=1144,44, p<0,01)$ değişkenlerinin hepsi beş ayrı kümede istatistiksel açıdan anlamlı farklılık sergilemektedir. Bu bulgu kümelerde yer alan araçların sayısal özellikleri bakımından birbirinden iyi bir şekilde ayrıştığını kanıtlamaktadır.

Tablo 5. Sürekli değişkenlere ilişkin ANOVA tablosu

\begin{tabular}{llrrrrr}
\hline & Varyansın Kaynağı & Kareler Toplamı & Sd & Kareler Ortalaması & F & $p$ \\
\hline \hline Fiyat & Gruplararası & $3,63175 \mathrm{E}+12$ & 4 & $9,08 \mathrm{E}+11$ & 9849,91 & 0,000 \\
& Gruplariçi & $6,07688 \mathrm{E}+12$ & 65926 & 92177257 & & \\
\multirow{3}{*}{ YıI } & Toplam & $9,70863 \mathrm{E}+12$ & 65930 & & & \\
& Gruplararası & 94373,57 & 4 & 23593,39 & 3197,22 & 0,000 \\
& Gruplariçi & 486490,36 & 65926 & 7,38 & & \\
Motor & Toplam & Gruplararası & 580863,93 & 65930 & & \\
Hacmi & Gruplariçi & 89434754,5 & 4 & 22358689 & \multirow{2}{*}{1144,44} & 0,000 \\
& Toplam & 1287979315 & 65926 & 19536,74 & & \\
& & 1377414070 & 65930 & & & \\
\hline
\end{tabular}




\subsection{Kümeleme Analizinin Performansının İncelenmesi}

Kümeleme çalışmalarında kümeleme işlemi gerçekleştirildikten sonra kümelemenin doğrulanması yönünde (cluster validity) analizlerin gerçekleştirilmesi gerekmektedir. Kümeleme doğrulamasını gerçekleştirecek göstergeler literatürde açıklanmaktadır (Gan vd., 2007:305314). Bu yöntemlere ek olarak Silhouette katsayılarını hesaplamak suretiyle de küme doğrulanması gerçekleştirilebilir (Kaufman ve Rousseeuw, 2005). Üstelik bu katsayılar yardımıyla silhouette grafiği de çizilebilir. Küme kalitesini bu şekilde görsel değerlendirme üstünlüğü sunduğundan dolayı çalışmada silhouette katsayıları ile doğrulama tercih edilmiştir.

Silhouette değerleri şu formül yardımıyla hesaplanmaktadır (Kaufman ve Rousseeuw, 2005:85):

$$
s(i)=\frac{b(i)-a(i)}{\max (a(i), b(i))}
$$

formülde $a(i)$ ifadesi $i$ nesnesinin aynı kümedeki diğer nesnelere ortalama uzaklığı ve $b(i)$ ifadesi ise $i$ nesnesinin farklı kümelerdeki noktalara ortalama uzaklıklarının en küçüğüdür. Silhouette değerleri $[-1,1]$ aralığında değişmektedir. Bu değerin yüksek olması, nesnenin kendi kümesi ile iyi eşleştiğini ve komşu kümelerle zayıf bir şekilde eşleştiğini ifade etmektedir. Yüksek $s$ değerlerinin olması kümeleme işleminin başarılı bir şekilde yapıldığını ifade ederken, düşük değerlerin olması kümeleme analizinin başarısız bir şekilde yapıldığına işaret etmektedir

Şekil 5. Silhouette Grafiği

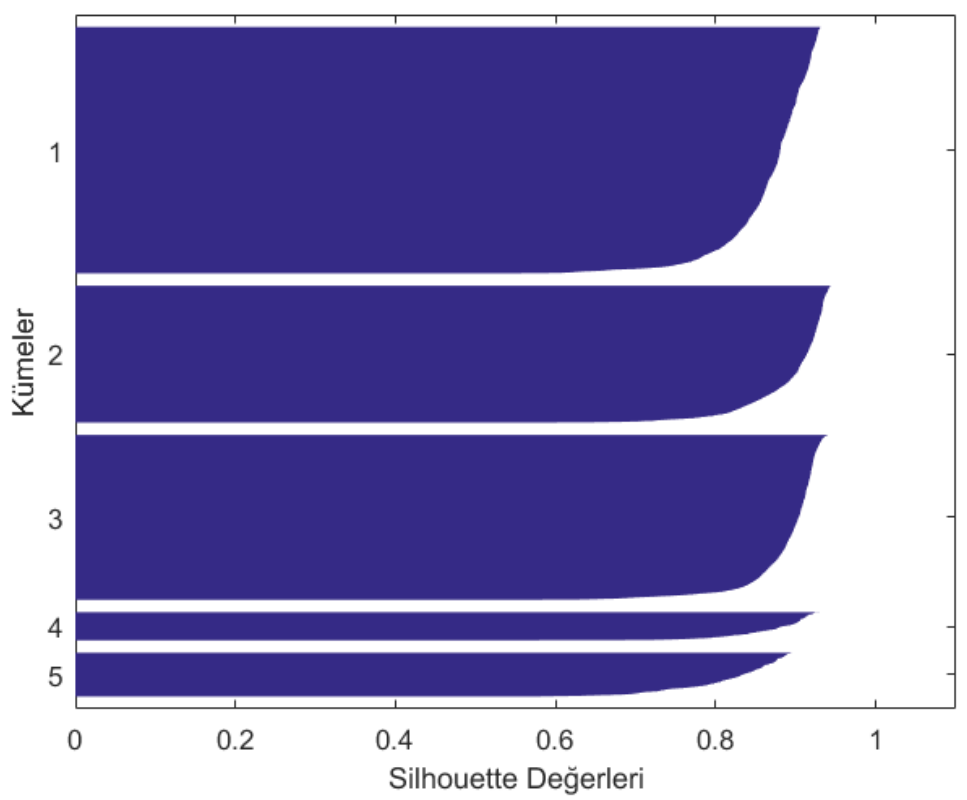

Şekil 5'de Silhoettte Grafiği görülmektedir. Her bir kümedeki nesnelerin Silhouette değerlerine ilişkin tanımlayıcı istatistikler Tablo $6^{\prime}$ da sunulmuştur. Tablodaki değerlerde negatif bir değerin olmadığı ve en düşük silhouette değerinin 0,4225 olduğu görülmektedir. Bu sonuçları 
göz önünde bulundurmak suretiyle özdüzenleyici haritalar yöntemi yardımıyla gerçekleştirilen kümeleme analizinin doğrulandığını söylemek mümkündür.

Tablo 6. Silhouette Değerlerine ilişkin tanımlayıcı istatistikler

\begin{tabular}{|c|c|c|c|}
\hline$s(i)$ & Min & Max & Ortalama \\
\hline Küme 1 & 0,4626 & 0,9306 & 0,8687 \\
\hline Küme 2 & 0,4775 & 0,9427 & 0,8955 \\
\hline Küme 3 & 0,4225 & 0,9403 & 0,8894 \\
\hline Küme 4 & 0,5160 & 0,9297 & 0,8684 \\
\hline Küme 5 & 0,5519 & 0,8943 & 0,8158 \\
\hline
\end{tabular}

\section{Sonuç}

Çalışmada Türkiye ikinci el oto piyasasının özdüzenleyici haritalar yardımıyla modellenmesi amaçlanmıştır. Bu amaçla mümkün olduğunca çok sayıda otomobile ilişkin bilgiler bir araya getirilmeye çalışıımıştır. Yapılan analiz sonucunda ikinci el oto piyasasında satışa sunulan araçlar kümelendirilmiştir. Piyasanın kaç adet kümeye ayrılacağı önceden bilinmemektedir. Bütün veri seti analiz edildiğinde araçların beş adet kümede toplandığı ortaya çıkmıştır. İkinci el arabaların fiyat, araç yaşı, kilometre ve güvenlik donanımı gibi araçlar için önemli olan kriterlere göre kümelere ayrılan bu çalışma, ikinci el araç satımı ile ilgilenen kişi ve kurumlara daha iyi pazarlama stratejileri geliştirmeleri için bir sistem sunmaktadır. Çalışma sonuçları aynı zamanda istatistiksel açıdan incelenmiş ve ortaya çıkan beş adet kümenin birbirinden oldukça farklı olduğu kararına varılmıştır. Bu çalışma ile birlikte literatürde ikinci el otomobil piyasasını farklı yöntemlerle modelleyen çalışmaların sayısının da artması beklenmektedir.

Çalışmada bazı kısıtlar mevcuttur. illk olarak nöron sayısı (veya harita boyutu) deneme yanılma yoluyla belirlenmiştir. İlerleyen çalışmalarda nöron sayısı farklı yöntemlerle belirlenebilir. Değişken seçimi için de uzman görüşlerinden faydalanılmıştır. Gelecek çalışmalarda (Hanafizadeh ve Mirzazadeh, 2011) çalışmasında olduğu gibi bulanık delphi yöntemi kullanmak suretiyle değişkenler seçilebilir. Çalışmada uzman görüşleri doğrultusunda altı adet değişken kullanılmıştır. İlerleyen çalışmalarda aracın kilometresi, yakıt türü, vergisi, boyutları, hasarlı parça sayısı gibi değişkenler de kullanılabilir. Daha geniş donanım ve daha büyük veri seti kullanmak suretiyle daha genel sonuçlara ulaşmak mümkün olabilir. Çalışmada kullanılan değişkenlerden biri de aracın fiyatıdır. Bazı ilanlarda pazarlık yapmak suretiyle, ilan fiyatından daha düşük fiyata alım gerçekleştirmek mümkün olabilecektir. İlerleyen çalışmalarda, erişilebilirse gerçek satış fiyatları kullanılabilir. 


\section{Kaynaklar}

Alpdoğan, Yılmaz; Bilge, Hasan Şakir (2009), “Kendinden Düzenlenen Harita Ağları İle Ders İçeriklerinin Sınıflandırılması”, Gazi Üniversitesi Mühendislik Ve Mimarlık Fakültesi Dergisi, C.24, S.2: 303-310.

Arı, Emin Sertaç; Özköse, Hakan; Doğan, Ahmet; Calp, M. Hanefi (2016), “istanbul Borsası’nda İşlem Gören Firmaların Finansal Performanslarının Kümeleme Analizi Ile Değerlendirilmesi”, Bilişim Teknolojileri Dergisi, C.9, S.1: 33-39.

Arribas-Bel, Daniel; Kourtit, Karima; Nijkamp, Peter (2013), "Benchmarking Of World Cities Through Self-Organizing Maps", Cities, Vol. 31: 248-257.

Asilkan, Özcan; Irmak, Sezgin (2009), “ikinci El Otomobillerin Gelecekteki Fiyatlarının Yapay Sinir Ağları İle Tahmin Edilmesi”, Süleyman Demirel Üniversitesi İktisadi Ve Idari Bilimler Fakültesi Dergisi, C.14, S.2: 375-391.

Badran, Fouad; Yacoub, Meziane; Thiria, Sylvie, (2005), "Self-Organizing Maps And Unsupervised Classification", Neural Networks Methodology And Applications, (Ed. Gerard Dreyfus), Springer-Verlag:Berlin/Heidelberg: 379442.

Bircan, Hüdaverdi; Zontul, Metin; Yüksek, Ahmet Gürkan (2006), "Som Tipinde Yapay Sinir Ağlarını Kullanarak Türkiye'nin İhracat Yaptığı Ülkelerin Kümelenmesi Üzerine Bir Çalışma”, iktisadi Ve Idari Bilimler Dergisi, C. 20, S.2: 219:239.

Canbaz, Mustafa; Çevik, Emre (2011), “imkb’de İşlem Gören Şirketlerin Sektörel Bazda Özörgütlenmeli Harita İle Finansal Risklerinin Belirlenmesi”, Iş̧letme Fakültesi Dergisi, C.12, S.2: 261-295.

Chen, Chiu-Chin; Chen, An-Pin; Yeh Pei-Yun (2013), "Modeling and Simulation of the Open-End Equity Mutual Fund Market In Taiwan By Using Self-Organizing Map", Simulation Modelling Practice And Theory, Vol. 36: 60-73.

Daştan, Hüseyin (2016), "Türkiye'de İkinci El Otomobil Fiyatlarını Etkileyen Faktörlerin Hedonik Fiyat Modeli İle Belirlenmesi”, Gazi Üniversitesi Iktisadi Ve Idari Bilimler Fakültesi Dergisi, C. 18, S.1: 303-327.

Demirhan, Ayşe; Güler, İnan (2010), “Özörgütlemeli Harita Ağları Ve Gri Düzey Eş Oluşum Matrisleri İle Görüntü Bölütleme”, Gazi Üniversitesi Mühendislik Ve Mimarlık Fakültesi Dergisi, C. 25, S.2: 285-291.

Dragomir, Otilia Elena; Dragomir, Florin; Radulescu, Marian (2014), "Matlab Application of Kohonen Self-Organizing Map To Classify Consumers' Load Profiles", 2nd International Conference On Information Technology And Quantitative Management, 31, 474-479.

Ecer, Fatih (2013), "Türkiye' De 2. El Otomobil Fiyatlarının Tahmini Ve Fiyat Belirleyicilerinin Tespiti”, Anadolu Üniversitesi Sosyal Bilimler Dergisi, C. 13, S. 4: 101-112.

Eklund, Tomas; Sarlin, Peter; Jokipii, Annukka (2011), "Visual Financial Benchmarking Using Self-Organizing Maps: A Revisit", Turku Centre For Computer Science, Http://Tucs.Fi/Publications/View/?Pub_id=Tsaekjo11a (Erişim: 17.08.2011).

Erdem, Cumhur; Şentürk, İsmail (2009), “A Hedonic Analysis Of Used Car Prices İn Turkey”, International Journal Of Economic Perspectives, Vol. 3, No. 2: 141-149.

Everitt, Brian S.; Landau, Sabine; Leese, Morven; Stahl, Daniel (2011), Cluster Analysis, West Sussex: Wiley Series in Probability And Statistics.

Fill, Chris (2009), Marketing Communications Interactivity, Communities And Content. New York: Prentice Hall.

Gan, Guojun; Ma, Chaoqun; Wu, Jianhong (2007), Data Clustering Theory, Algorithms And Applications, Philadelphia: Asa-Siam Series On Statistics And Applied Probability.

Hanafizadeh, Payam; Mirzazadeh, Meysam (2011), "Visualizing Market Segmentation Using Self-Organizing Maps And Fuzzy Delphi Method - Adsl Market Of A Telecommunication Company", Expert Systems With Applications, Vol. 38, No. 1: 198-205.

İnce, Hüseyin; İmamoğlu, Salih Zeki; Keskin, Halit (2013), “Öz-Düzenlemeli Harita Ağları İle K-Ortalama Kümeleme Analizinin Karşılaştırılması: Tüketici Profilleme Örneği”, Gazi Üniversitesi Mühendislik Ve Mimarlık Fakültesi Dergisi, C. 28, S.4: 723-731.

Kaski, Samuel (2011), "Self-Organizing Maps”, Encyclopedia Of Machine Learning, (Ed. Claude Sammut Ve Geoffrey I. Webb), Springer Reference: New York, 886-888.

Kaufman, Leonard; Rousseeuw, Peter J. (2005), Finding Groups in Data: an Introduction to Cluster Analysis, New Jersey: Wiley-Interscience.

Kohonen, Teuvo (2001), Self-Organizing Maps, Espoo: Springer Series In Information Sciences. 


\section{Eskişehir Osmangazi Üniversitesi ïiBF Dergisi}

Kutlu, Yakup; Kuntalp, Mehmet; Kuntalp, Damla (2008), “Özdüzenleyici Haritalar Kullanılarak Diken Dalgaların Analizi", Genç Bilim Insanları Ve Beyin Biyofiziği Iı. Çalıştayı. İzmir.

Kutlu, Yakup; Kuntalp, Mehmet; Kuntalp, Damla (2009), “Ekg Vurularının Morfolojik Özniteliklerinin Topografik Analizi". 14th National Biomedical Engineering Meeting, İzmir.

Louis, Philippe; Seret, Alex; Baesens, Bart (2013), "Financial Efficiency and Social Impact of Microfinance Institutions Using Self-Organizing Maps", World Development, Vol. 46: 197-210.

Mehrotra, Kishan; Mohan, Chilukuri K.; Ranka, Sanjay (1996), Elements of Artificial Neural Networks, Cambridge: The MIT Press.

Oğuzlar, Ayşe (2009), "Kümeleme Analizinde Yeni Bir Yaklaşım: Kendini Düzenleyen Haritalar (Kohonen Ağları)", Atatürk Üniversitesi Iktisadi Ve Idari Bilimler Fakültesi Dergisi, C. 19, S. 2: 93-107.

Öz, Bülent; Taban, Sami; Kar, Muhsin (2008), “Kümeleme Analizi İle Türkiye Ve Ab Ülkelerinin Beşeri Sermaye Göstergeleri Açısından Karşılaştırılması”, Eskişehir Osmangazi Üniversitesi Sosyal Bilimler Dergisi, C. 10, S. 1: 1-30.

Özçalıcı, Mehmet (2011), Özdüzenleyici Haritalar Yöntemi Ile Banka Müşterilerinin Bölümlendirilmesi. Gaziantep Üniversitesi Sosyal Bilimler Enstitüsü, Yüksek Lisans Tezi.

Özçalıcı, Mehmet (2016), “Hisse Senetlerinin Özdüzenleyici Haritalarla Kümelendirilmesi: Bıst50 Endeksinde Yer Alan Hisseler Üzerine Bir Uygulama”, İstanbul Üniversitesi Iş̧letme Fakültesi Dergisi, C. 45, S. 1: 22-33.

Özşahin, Metin; Yüreğir, Oya H. (2012), “Otomotiv Sektörünün Kendini Örgütleyen Haritalar Ile Finansal Analizi”, Ç.Ü. Fen Ve Mühendislik Bilimleri Dergisi, C. 28, S. 2: 155-164.

Şekerkaya, Ahmet; Cengiz, Emrah (2010), "Kadın Tüketicilerin Alışveriş Merkezi Tercihlerinin Belirlenmesi ve Bir Pilot Araştırma", Öneri, C. 9, S. 34: 41-55.

Taşkın, Çağatan; Emel, Gül Gökay (2010), "Veri Madenciliğinde Kümeleme Yaklaşımları ve Kohonen Ağları İle Perakendecilik Sektöründe Bir Uygulama”, Süleyman Demirel Üniversitesi Iktisadi Ve Idari Bilimler Fakültesi Dergisi, C. 15, S.3: 395-409.

Ünal, Sevtap; Erciş, Aysel, (2004), “Banka Hizmetleri Satın Alan Tüketicileri Banka Özellik ve Hizmet Değişkenlerine Yönelik Tutumlarına Göre Alt Pazar Bölümlerine Ayırma Üzerine Erzurum'da Bir Araştırma”, Atatürk Üniversitesi Sosyal Bilimler Enstitüsü Dergisi, C. 4, S. 2: 287-304.

Xia, Yu; Chen, Bintong; Jayaraman, Vaidyanathan; Munson, Charles L. (2015), "Competition and Market Segmentation of the Call Center Service Supply Chain", European Journal Of Operational Research, Vol. 247, No. 2: 504-514.

Yeh, Wei-Chang; Lai, Chyh-Ming; Chang, Kuei-Hu, (2016), “A Hybrid Clustering Approach Based on K-Harmonic Means Using Robust Design", Neurocomputing, Vol. 173: 1720-1732. 